\title{
Web based Courses Using Video Components
}

I. Stiubiener, R.M. Silveira, W.V. Ruggiero

LARC - Department of Electrical Engineering of Universidade de São Paulo Av.Prof. Luciano Gualberto, trav. 3 - 158, sala C1-46, 05508900 SP, Brasil . itana@larc.usp.br, regina@larc.usp.b, wilson@larc.usp.br

\section{Index Terms - automation learning teaching process, online learning, multimedia, and Web applications.}

Abstract: This work presents some considerations about the process of producing and utilization of video components in Web based courses. We discuss some aspects related with the infrastructure necessary to produce and deliver this material and we present also some conclusions of our experience in producing our Web based courses using video elements.

When we consider a Distance Teaching-Learning environment there's a consensus that the employment of multimedia elements is almost obligatory if we want to catch and maintain student's interest and attention.

Specifically talking about the use of the video in this environment we have many considerations that range from production cost to the effective benefits on student's attention.

This paper aims at presenting some experience, some problems and some conclusions we achieved when producing our video course. It'll be presented in 6 topics that define the main aspects we observed in this process.

The first aspect in producing a video classroom is that usually teachers of an engineering school aren't prepared to speak in front of a video camera. They aren't prepared to speak with lights and phones and all paraphernalia that is usually necessary in a video production. A teacher is concerned about teaching the content of his/her course, the best strategies to transmit his/her knowledge, the best strategies to provoke student's interest and what is the best way to evaluate his/her students.

At the same time it's almost impossible to hire a specialized professional to record an engineering educational video because the subjects are very difficult for a non-engineer professional to understand. The time that an actor would demand to learn a simple technical subject has a magnitude that is impracticable if we imagine the time required to produce a complete Web based course program.

The second aspect is the physical space that is required to prepare and record this material. When we think about that we start with some considerations that are totally outside of our knowledge area such as illumination, acoustics, wall colors and even teacher's clothes colors. 
When we started recording our classes at São Paulo University, we found many problems such as:

- illuminations problems - to solve these problems we bought some specific lights and filters that consist of professional cinematography equipment;

- acoustics problems - as we weren't prepared for these situations when we started with our video class production, we discovered that we didn't have a space with a acoustic response compatible with the cinema industry and if you don't solve this problem in the end you achieve a very bad quality of the audio component;

- environment color - walls colors and teachers' clothes colors have a direct influence on the video final quality. Nowadays we recommend our teachers not to ware white clothes when they have to record a class. We also utilize special classrooms with chrome-key wall for future editions.[1]

It's easy to see that a video class production isn't easy to implement and demands efforts that extrapolate engineering domains.

The third very important aspect that appears is the need of a very specific equipment and specialized team to transform a class video in a digital file. Producing an educational video is a very time-consuming task and requires specialized people in recording, editing and producing this video. We must be able to manage this team and also we must maintain their motivation in producing this kind of material. To achieve this motivation we have to change and try to create new class formats. We also need good equipment to motivate this team and at the same time have a good quality of our classes that are recorded.

After we have our course that utilizes a complete video class or some video explanation parts it's recommendable to have a team with professionals like pedagogues, psychologists and specialized personnel in communications theories. This is due to the fact that as engineers we aren't well prepared to analyze the real meaning of these elements in students learning process. A big engineering achievement is the video Web production but is it an effective benefit to students? We strongly believe that only personalized professional can answer these questions and we are now trying to work with a multidisciplinary team.

The fourth one is due to the fact that as the video size is very big and consumes a lot of memory video it is necessary a very specific and expensive hardware to compress and transform the video in a digital file. It is necessary also to have a big hardware infrastructure to store all this material. We have some results that show that this need of 
memory is a continuously and increasing need and we believe that it's interesting to do a project before start recording.

We now have:

- for 1 hour video classroom:

- transmission rate $22 \mathrm{Kbits} / \mathrm{seg}$

$\rightarrow 1,2$ Gbytes memory to the video file edited and rendered

$\rightarrow 10$ Mbytes memory to the final format to the streaming server

- transmission rate $100 \mathrm{Kbits} / \mathrm{seg}$

$\rightarrow 1,2$ Gbytes memory to the video file edited and rendered

$\rightarrow 45$ Mbytes memory to the final format to the streaming server

As each of our graduate courses lasts a minimum of 40 hours we are now doing a backup in a DAT device and we aren't saving the edited files because of their dimensions.

The fifth aspect consist of the infrastructure we have to define and implement to provide without interruptions, our Web based classes. If we consider that we have already a big problem when we want to provide this service without video utilization it is not difficult to see that the video utilization brings bigger problems. The first consideration is that it's necessary to have a video server in the network. This server must be able to attend to many requests at the same time so it is necessary to specify a very potent machine that has a very good performance and also has a disk array. The second consideration is that when we use a video element in a course we have to consider the quality of this video will present to students and this quality has a strongly relationship with the network bandwidth. The best configuration is when students have a high connection to our servers.

The last but a very important aspect is that it's necessary to provide a mechanism to publish automatically this video on the Web. To reach this feature we developed a tool that does this and also synchronizes our video with other material like texts, pictures, PowerPoint transparences, animations, links to other sites, etc according to our teacher's will. With this tool we not only get an efficient way to publish by everyone the Web class but also we don't need any extra work from the teacher whom can only direct the construction of he/she's course. [2], [3].

\section{Conclusions}

We presented here many aspects that evolve video utilization and production. We believe that we're still researching the best way to use and produce our video classrooms but also that, besides all problems pointed a Web based course using video elements is more stimulating and a very rich educational material. 


\section{References}

[1] R.M. Silveira*, O.D.Vilcachagua*, V.B. Dias*, T.C.M.B. Carvalho*, W.V. Ruggiero* and A.M.A. Massola, "VIRTUALIZING THE POLYTECHNIC SCHOOL OF UNIVERSITY OF SAO PAULO",ASEE Annual Conference Proceedings 2001 (Submitted)

[2] Stiubiener,I R.M. Silveira, W.V. Ruggiero “WEB-BASED COURSES PRODUCTION AUTOMATION”, ASEE Annual Conference Proceedings 2001 (Submitted)

[3] Stiubiener,I..Ceze,L.H.Strauss,K.Margi,C.B.Silveira,R.M.Ruggiero,V.W. "AUTOMATING THE WEB LEARNING-TEACHING PROCESS". Internationl Conference in Engineering Education ICECE 2000, São Paulo, Brazil, August 2000.

[4] I. Stiubiener, L.H. Ceze, K. Strauss, C.B. MargiR.M. Silveira, W.V. Ruggiero"AN ONLINE WEB COURSE ENVIRONMENT AND ITS APPLICATION", FIE2000 - Frontiers in Education, , Kansas City, US, Outubro/2000

[5] I. Stiubiener, L.H. Ceze, K. Strauss, C.B. MargiR.M. Silveira, W.V. Ruggiero "AN ENVIRONMENT FOR EASY CROSS-SYNCHRONIZATION OF MULTIMEDIA WEB BASED MATERIAL", a ser apresentado no FIE2000 - Frontiers in Education, Kansas City, USA Outubro/2000.

\section{Itana Stiubiener}

Itana Stiubiener is courrently a doctoral student at the University of São Paulo. She received her B.S. Electrical Engineering from Escola de Engenharia Mauá and M.S. in Computer Engineering from University of São Paulo. Before returning to graduate school to dedicate her carrier to reseach on education she spent 10 years in industries working with software development. In addition to research, she teaches a Client-Server Extension course to outside students and network labs to undergraduated students at University of São Paulo.

\section{Regina Melo Silveira}

Regina M. Silveira received the B.S. degree in Physics from Catholic University of São Paulo (PUC-SP) in 1988. In 1994, she received the M.S. degree in Physics from University of São Paulo, São Paulo, and Brazil. In 2000 she degree Ph.D. in the Department of Computer and Digital System engineering at the Polytechnic School of University of São Paulo, Brazil. She is teacher and researcher at LARC (Laboratory of Computer Architecture and Networks) where she has developed projects at multimedia applications for high-speed network and distance education

\section{Wilson Vicente Ruggiero}

Wilson Vicente Ruggiero is President of SCOPUS TECNOLOGIA S.A. He is an assistant professor of Computer Department and Digital Systems Engineering of Polytechnic School of University of São Paulo and Director of Laboratory of Computer and Networks ( LARC) of Polytechnic School University of São Paulo .He received his degree in Electrical Engineering in 1971 in University of São Paulo. His B.S degree in 1975 in University of São Paulo and his PhD by UCLA University in 1978.

Proceedings of the 2001 American Society for Engineering Education Annual Conference \& Exposition Copyright Ó 2001, American Society for Engineering Education 